\title{
O conflito como manifestação da dimensão política dos enfermeiros na implementação do PMAQ-AB
}

\author{
Conflict as a manifestation of the political dimension of nurses' work \\ in primary care: the case of $P M A Q-A B$
}

Tânia Silva Gomes Carneiro', Pedro Silveira Carneiro', Ione Carvalho Pinto'

DOI: 10.1590/0103-1104202012502

\begin{abstract}
RESUMO Neste estudo, considera-se como dimensão política a relação que os trabalhadores estabelecem com a gestão pública em saúde e seus desdobramentos no trabalho na Atenção Básica (AB) nas modalidades de organização da AB. Objetivou-se discutir o conflito entre enfermeiros da AB e gestão municipal em torno da contratualização e recontratualização ao Programa Nacional de Melhoria do Acesso e da Qualidade da Atenção Básica (PMAQ-AB) como manifestação da dimensão política. Estudo de caso instrumental e qualitativo, alicerçado na Análise de Discurso de matriz francesa. O corpus constituiu-se por entrevistas semiestruturadas com oito enfermeiros, informantes-chave da $\mathrm{AB}$ municipal de Ribeirão Preto (SP), e por documentos de planejamento de cinco quadriênios de gestão. Observa-se uma transição incompleta do modelo de $\mathrm{AB}$, mais como mistura do que de transição, com uma implantação incipiente da Estratégia Saúde da Família. Fica claro que a relação entre enfermeiros e gestão não é de confiança, nem de corresponsabilidade. Não há perspectiva de participação nos processos de decisão relativos ao PMAQ-AB, cuja condução privilegiou os aspectos burocráticos esvaziando a política de avaliação de sentido para os trabalhadores. Apesar de responsabilizarem a gestão, os enfermeiros se limitam a formas de resistência pontuais, em um contexto de ausência de negociação coletiva.
\end{abstract}

PALAVRAS-CHAVE Atenção Primária à Saúde. Enfermagem em saúde comunitária. Gestão em saúde. Sistema Único de Saúde. Política de saúde.

ABSTRACT This study considers the political dimension as the relationship that workers have with the public health management at work and its developments in Primary Care (PC) services in different modalities of PC organization. It seeks to discuss the conflict between PC nurses and management regarding the contratualization and recontratualization of the National Program for Access and Quality Improvement in Primary Care $(P M A Q-A B)$ as a manifestation of the political dimension. It is an instrumental and qualitative case study grounded on French discourse analysis. The corpus was constituted by semi-structured interviews with 08 nurses, key informants from the PC of Ribeirão Preto (SP), as well as planning documents of five quadrennium of municipal administration. Data points to an incomplete transition of the PC model, more of a mixture than a transition, with an incipient use of the Family Health Strategy. The relationship between nurses and management lacks trust and coresponsibility. There is no perspective of participation in decision-making processes around the $P M A Q-A B$, whose implementation focused on bureaucratic aspects while emptying the policy of evaluation of meaning for workers. Despite holding management responsible, nurses are limited to

1 Universidade de São Paulo (USP) - São Paulo (SP),

Brasil.

jasmimgomes@yahoo.

com.br 


\section{Introdução}

Consolidar a efetivação do processo da Reforma Sanitária Brasileira (RSB) incide em discussões sobre os desafios atuais e sobre o futuro do Sistema Único de Saúde (SUS), debatidas por diversos autores e entidades do campo da saúde coletiva, comprometidos com a institucionalização da saúde como direito de cidadania' ${ }^{1-4}$.

"A dimensão sociopolítica contempla as ações voltadas para obter o apoio da população às políticas do SUS"'1(912). Seria natural que a efetivação do SUS fosse defendida pela maioria da população, mas, concretamente, é necessário que as pessoas percebam as vantagens do SUS para que o defendam'. Nesse sentido, a participação popular se constitui uma estratégia importante; já que o SUS tem como proposta a democratização, não é possível negligenciar ações que fortaleçam a participação de usuário, trabalhadores e prestadores na construção e implementação de políticas de saúde.

Conforme vem sendo discutido nesse último período, em que o SUS completa 30 anos sob diversos ataques de viés privatista ${ }^{2,3}$, apesar de seus avanços, como, por exemplo, ampliação da cobertura de Atenção Básica (AB) ${ }^{2}$, ele sofre uma série imensa de obstáculos por parte de diversos setores da sociedade brasileira. Inclusive, conforme coloca Paim2(1725), "o SUS sofre resistências de profissionais de saúde, cujos interesses não foram contemplados pelas políticas de gestão do trabalho e educação em saúde".

Entende-se que a $\mathrm{AB}$, que compõe um importante campo de trabalho de profissionais de saúde no SUS e um espaço de disputa da mudança das práticas profissionais, pode ser um espaço de reflexão crítica e, também, de contra-hegemonia. Nessa perspectiva, faz-se necessário constituir um bloco de agentes sociais que sustentem o SUS enquanto projeto civilizatório ${ }^{\mathbf{2 , 4}}$.

Ao se considerar que, de 2.054 Equipes de Saúde da Família (EqSF) em 1998, chegou-se, em 2017, a 41.619 equipes, o que corresponde a um salto de $4,4 \%$ para cerca de $70 \%$ de cobertura de pessoas cadastradas pela Estratégia Saúde da Família (ESF) ${ }^{5}$, pode-se dimensionar a potencialidade de uma parceria entre os trabalhadores e os usuários da $\mathrm{AB}$ em um movimento de afirmação do SUS ${ }^{6}$. Considerando o contingente de enfermeiros inseridos nas equipes na $\mathrm{AB}$, é central ter esses trabalhadores como sujeitos políticos na luta pelo avanço da RSB e do SUS constitucional.

Discutindo aspectos do trabalho em enfermagem, Almeida7 coloca como dimensões inerentes ao trabalho gerencial a "técnica, a política, comunicativa e o desenvolvimento da cidadania"7(288). Segue definindo a dimensão política como:

\begin{abstract}
Aquela que articula o trabalho gerencial ao projeto que se tem a empreender, a consolidação do SUS. Neste movimento se fazem presentes determinações de caráter político-ideológicas, econômicas, assim como as marcadas pelas organizações corporativas e pelos distintos tipos de usuários dos serviços de saúde. Implica, sem dúvida, a articulação do momento mais interno do processo de trabalho as determinações externas deste, que dizem respeito às políticas sociais e de saúde em específico e das contradições e conflitos presentes na sociedade para sua efetivação7(289).
\end{abstract}

A articulação entre o 'processo de trabalho' e as 'determinações externas' se concretiza na relação entre os trabalhadores da saúde e a gestão, de tal forma que se considera como dimensão política a relação que os trabalhadores estabelecem com a gestão pública em saúde e seus desdobramentos no trabalho na $\mathrm{AB}$ nas distintas modalidades de organização da $\mathrm{AB}$.

Destarte, este artigo se propõe a discutir um dos aspectos que emergiram ao se analisar a dimensão política em pesquisa de doutorado da qual este artigo é fruto, que foi o conflito entre os trabalhadores de saúde da $\mathrm{AB}$ e a gestão municipal em torno da contratualização e recontratualização ao Programa Nacional de Melhoria do Acesso e da Qualidade da Atenção Básica (PMAQ-AB).

O PMAQ-AB foi criado em 2011 com intuito enunciado de ampliar o acesso e a melhoria da qualidade da $\mathrm{AB}$, por meio da "instituição de processos contínuos e progressivos de avaliação 
e monitoramento que pudessem fortalecer a capacidade das três esferas de governos de ofertar serviços"8(572) com garantia de um padrão de qualidade

comparável nacional, regional e localmente de maneira a permitir maior transparência e efetividade das ações governamentais direcionadas à Atenção Básica em Saúde9,10.

Representou uma continuidade de um progressivo processo de avaliação institucional dentro do SUS, porém, "diferenciando-se, todavia, por ter um escopo abrangente, principalmente por vincular o processo avaliativo a incentivos financeiros por desempenho"8(571). Foi criado como base para distribuição de novos recursos financeiros para AB8 denominado Componente de Qualidade do Piso de Atenção Básica (PAB) Variável9,10, um incentivo que, em parte, depende do desempenho das equipes na avaliação.

O primeiro ciclo (2011-2012) desse programa ficou direcionado para a avaliação da ESF, porém, já no segundo ciclo (2013-2014), foram definidos "Critérios de Parametrização e Equivalência das Diferentes Modalidades de Organização da Atenção Básica com a Estratégia Saúde da Família"11(29), incluindo outras formas de organização da $A B$ na avaliação.

O PMAQ-AB, em seus dois ciclos, foi composto por quatro fases complementares que constituem um processo de melhoria do acesso e da qualidade da $A B$ : a adesão e a contratualização (primeira fase), o desenvolvimento (segunda fase), a avaliação externa (terceira) e a recontratualização (quarta fase), que representa o início do novo ciclo, ${ }^{9,10}$.

No terceiro ciclo, iniciado com a adesão das equipes em 2015, mas com realização da avaliação externa postergada até 2017 , por conta da crise de governabilidade e políticas de austeridade fiscal que cortaram fortemente as receitas do SUS, as fases foram reagrupadas em três. A fase de desenvolvimento foi reorganizada e transformada em eixo estratégico transversal, que deve ser realizada de forma permanente ${ }^{8(572)}$.
É importante ressaltar que a fase quatro, recontratualização, posterior à certificação das equipes, que se propõe a ser um momento de nova pactuação de indicadores e dos processos de trabalho, teoricamente confere ao programa um caráter cíclico e contínuo de melhoria. Para que seja possível aferir, ao longo do tempo, essa melhoria, no entanto, seria essencial a continuidade e a comparabilidade entre os ciclos ${ }^{8}$.

Dessa forma, objetivou-se, neste artigo, discutir o conflito entre enfermeiros da $\mathrm{AB}$ e gestão municipal em torno da contratualização e recontratualização do PMAQ-AB como manifestação da dimensão política.

\section{Material e métodos}

Trata-se de um estudo de caso, do tipo instrumental' ${ }^{12}$, alicerçado pela abordagem qualitativa e pelo referencial teórico-metodológico da Análise de Discurso $(\mathrm{AD})$ de matriz francesa, que, epistemologicamente, funde-se em uma filosofia linguística, materialística e psicanalítica ${ }^{13}$.

O estudo foi realizado no município de Ribeirão Preto (SP), pertencente à Rede Regional de Atenção à Saúde (RRAS) 13 do estado de São Paulo, com população municipal estimada de 694.534 ${ }^{14}$. Possui 46 estabelecimentos, distribuídos nos Distritos de Saúde, sendo 25 Unidades Básicas de Saúde(UBS), 19 Unidades de Saúde da Família (USF) e 2 Unidades Básicas e Distritais de Saúde (UBDS) ${ }^{15}$.

Para melhor compreender a rede de serviços da AB municipal, foram levantados aspectos estruturais e organizativos de todas as unidades descritos nos documentos de planejamento municipal, sendo possível identificar distintos arranjos organizativos na rede.

Para o escopo deste estudo, definiram-se quatro modalidades de organização da $\mathrm{AB}$ presentes no município, a partir da incorporação (ou não) de elementos da ESF: UBS Tradicional (sem nenhum elemento de saúde da família); UBS com Agente Comunitário de Saúde (ACS); USF adaptada (com médicos nas especialidades básicas: ginecologista, pediatra e clínico); USF pura (somente com 
EqSF). Não foram incluídas unidades com pronto atendimento ou terceirizadas.

Definiu-se, também, para o escopo do estudo, que seriam incluídos na investigação somente profissionais com jornada integral na rede de AB municipal, ou seja, jornada de 40 horas, critério que faz parte da recomendação da Política Nacional de Atenção Básica vigente ${ }^{16} \mathrm{e}$ vínculo com a administração direta municipal. Chegou-se a 39 enfermeiros, distribuídos entre 23 unidades de saúde.

Aplicaram-se, a esses sujeitos, os seguintes critérios de exclusão: estar alocados em cargos de chefia ou gerência; estar de férias, licença saúde, licença maternidade ou outras causas de afastamento; não atender à pesquisadora em três tentativas de visita à unidade. Após esses critérios, em um contato inicial, oito sujeitos não aceitaram participar do estudo. Chegou-se a 24 sujeitos em potencial.

Dentre estes, foram escolhidos 10 informantes-chave de interesse, usando como critério ter participação no primeiro ciclo do PMAQ-AB tendo em vista a importância dada pelos enfermeiros ao conflito com relação ao processo de avaliação durante a exploração inicial do campo. Foi possível entrevistar oito informantes no período da realização das entrevistas (uma estava afastada por licença saúde e outra havia sido transferida para um serviço da atenção secundária).

Os dados foram coletados nos meses de fevereiro a abril de 2014, por meio da realização de entrevistas semiestruturadas, utilizando roteiro. As entrevistas foram gravadas e transcritas literalmente, totalizando 6 horas e 32 minutos. Utilizouse, também, a análise documental como técnica de coleta de dados, buscando (re)constituir o contexto sócio-histórico da organização da rede de $\mathrm{AB}$ na qual estão inseridos os sujeitos do estudo, a partir de documentos oficiais de planejamento municipal em saúde.

Consideraram-se, como documentos de interesse, os Planos Municipais de Saúde e os Relatórios Anuais de Gestão ${ }^{17}$, desde o início da implantação do Programa Saúde da Família em 1997, correspondendo a cinco quadriênios de gestão municipal (1997 a 2000; 2001 a 2004; 2005 a 2008; 2010 a 2013; 2014 a 2017). Não foi possível o acesso ao Plano Municipal de Saúde de 1997 a 2000 e ao Relatório de Gestão de 2001 a 2004.

O corpus de análise desta pesquisa foi constituído por entrevistas semiestruturadas (material empírico) e pelos documentos mencionados (arquivos). Na perspectiva discursiva ${ }^{\mathbf{1 8}}$, é a partir de um 'recorte' de dados determinado pelas condições de produção que se pode falar na construção do corpus, levando-se em conta os objetivos e princípios teóricos que, orientando toda a análise, possibilitaram uma análise objetiva dos dados. A linearização do discurso é apresentada sob a forma de sequências discursivas de referência a partir de recortes da fala dos enfermeiros sobre o PMAQ-AB.

A pesquisa foi aprovada pelo Comitê de Ética em Pesquisa daEscola deEnfermagem de Ribeirão Preto da USP, sob parecer $\mathrm{n}^{\circ}$ 537.514, CAAE: 13958013.7.0000.5393, atendendo à Resolução $n^{\circ} 466 / 12$. As entrevistas foram realizadas após leitura e anuência do Termo de Consentimento Livre e Esclarecido (TCLE), sendo garantidos o anonimato e o sigilo das informações relativas a cada indivíduo.

\section{Resultados e discussão}

A configuração das trabalhadoras de saúde entrevistadas foram enfermeiras com idade entre 37 anos e 59 anos, tempo de formação entre 15 anos e 36 anos, e tempo de atuação na $\mathrm{AB}$ municipal entre 9 anos e 24 anos. Entende-se que essas diversas vivências acumuladas durante esse tempo de trabalho influencia a representação que essas enfermeiras têm da $\mathrm{AB}$.

Na análise dos documentos oficiais de planejamento municipal em saúde, encontrou-se uma particularidade da política de saúde municipal para a reorganização da $\mathrm{AB}$, tendo como proposta a ESF, porém sem a substituição do modelo tradicional representado pelas UBS. Observou-se, do ponto de vista histórico, uma sucessão de gestões municipais em que as metas relativas à reorganização da $\mathrm{AB}$ são repetidamente descumpridas, com significativa descontinuidade 
com relação a metas de cobertura de ESF e $\mathrm{AB}$ do ponto de vista de série histórica de dados.

Essa estratégia adotada pelo município surge no discurso das enfermeiras E8 e E2, que contam como foi a integração das EqSF nas UBS do município, atuando na mesma planta física e com aproveitamento dos profissionais já existentes, referida pelos profissionais como Unidade mista:

[...] 'quando eu trabalhei em saúde da família, inicialmente em 2000', eu estava em uma unidade básica, que não era só saúde da família, [...] essas duas equipes de saúde da família funcionaram ali, 'dentro da mesma planta física, tendo as duas modalidades, tinham duas equipes de saúde da família junto com um convencional da unidade básica e não dava certo' [...] A população não entendia, mesmo nós profissionais, a gente fazia metade da carga horária na unidade convencional e metade só da carga horária em PSF e não virava. [...] [o médico] I[ginecologista] de manhã e à tarde ele tinha uma agenda de PSF... sabe? mas não dava certo. [...] não vinculava com a comunidade ali que era do PSF, os pacientes não entendiam. (E8).

[...] essa ideia [de implantar o PSF] não pegou, 'essa ideia não foi bem aceita', porque depois, logo em seguida [da implantação do PSF] eu fui para a ponta e vivi amargamente os anos vindouros, é.... dessa ideia instaurada. [...] Sabe o que eu acho de verdade... é que as unidades têm que ser com propósitos diferentes, 'não adianta você misturar'. (E2).

No discurso de E2, encontrou-se um conflito entre os profissionais dos distintos modelos caracterizado nas sequências discursivas destacadas, remetendo a um processo de resistência dentro das unidades mistas, como se vê no trecho:

[...] 'Você coloca mais gente dentro de um lugar que não cabe mais gente' e que pensa diferente... que $1 / 5$ daquela população, daquela unidade está querendo trabalhar uma proposta e uma filosofia de saúde diferente e 4/5 não quer, quer continuar do jeito que está. Então 'é um jogo de força muito grande' [...]. (E2).
Conforme visto nas sequencias discursivas acima, os enfermeiros fazem referência a um tensionamento entre trabalhadores e gestão relativo à implantação da ESF no município, que parece permanecer durante todo o período, ao se considerar o contexto de descontinuidade observado na análise documental. Essa mistura de diferentes tipos de equipe não foi exclusiva do município estudado, conforme avaliado no Projeto de Expansão e Consolidação da Saúde da Família (Proesf) em 2007, que coloca que essas situações onde existem unidades puras, outras que incorporam parte da equipe, outras em que convivem os dois modelos

constituem desafios para os trabalhadores do sistema, pois geram variações significativas nas demandas de produção, nas relações no seio da equipe e nas suas atividades ${ }^{18(110)}$.

Entende-se que são nessas condições sócio-históricas que emergem os discursos dos enfermeiros sobre o PMAQ-AB na AB municipal, que interessa analisar neste artigo.

No processo de condução do PMAQ-AB no município, é perceptível, nos discursos dos enfermeiros, que a gestão buscou induzir os trabalhadores a participarem a partir de uma promessa de recursos advindos da adesão do município ao PMAQ-AB, como forma de viabilizar melhorias nas Unidades participantes. Posteriormente, no entanto, essa promessa não se cumpriu e gerou uma importante frustação nas equipes participantes.

É assim... o primeiro ano do $P M A Q-A B$ 'o recurso financeiro era para ser usado para a unidade participante', né? Então... tanto é que ele 'foi proposto voluntariamente, quem quisesse participar, participaria'. Então isso foi uma proposta para todos, então 'se a unidade participasse ela teria um recurso para ser usado para melhoria' dos seus instrumentos, dos seus recursos da unidade em prol da comunidade que a gente atendia, né? (E5).

A enfermeira E5 remete ao recurso que seria disponibilizado como uma forma de recompensa 
que seria repassada para a unidade participante mediante a adesão ao PMAQ-AB, para melhorias do trabalho, e ressalta a participação voluntária. No conjunto dos discursos dos enfermeiros, fica subentendido que a motivação para a adesão é a perspectiva de recompensa.

Ao analisar o PMAQ-AB, Moraes et al. ${ }^{19(423)}$ colocam que:

Embora nos documentos oficiais não haja previsão de remuneração por desempenho, existem experiências, em alguns municípios, em que os recursos do componente de qualidade do PAB Variável são empregados, no todo ou em parte, em bonificação no rendimento dos trabalhadores. Boa parte dos municípios, se não revertem diretamente aos trabalhadores das suas equipes de atenção básica, pelo menos, parte do componente de qualidade do PAB Variável, o fazem indiretamente com investimentos que podem significar uma melhoria das condições de trabalho.

O município teve como meta, no ano de 2012, implantar o PMAQ-AB em 12 equipes, e atingiu como resultado a implantação em 19 equipes ${ }^{20}$. No momento do estudo, estava prevista, no Plano Municipal de Saúde, a ampliação de 35 para 42 equipes aderidas ao PMAQ- $\mathrm{AB}^{\mathbf{2 1}}$.

Essa estratégia de estímulo e indução adotada pelo município, centrada em um sistema de recompensa que atingisse diretamente a unidade participante, fez com que os trabalhadores incorporassem esse recurso como algo que seria da equipe, em uma postura antissolidária: [...] também parece que 'nosso dinheiro', o primeiro e o segundo [ciclos do PMAQ-AB], tudo que foi liberado, 'não foi usado para nós' [...]”' (E2). Assumindo um sentido de competição entre unidades por recursos, conforme observa-se no trecho discursivo a seguir:

[...] foi usado esse recurso [da adesão ao PMAQAB] em coisas, depois assim... diferentes do que pactuado, né? Seria utilizado para a Atenção Básica como um todo, inclusive com as unidades que não tinham participado e a unidade achava que tudo bem, se a gente tivesse utilizado, 'o recurso que sobrasse poderia ser usado com as outras unidades', mas a princípio teria que ser assim... o pacto teria que ser cumprido com a unidade participante [...]. (E5).

As sequências discursivas destacadas de $\mathrm{E} 2 \mathrm{e}$ E5 remetem ao sentido que foi introjetado pelo trabalhador nas unidades participantes, de um recurso que lhes pertence e que não deveria ser usado com outros fins, reforçando o sentido de competição, como destacado acima. Isso corrobora o fato de que "A forma de concorrência estabelecida pelo PMAQ-AB não é individual, mas sim por equipes"19(424). Concorrência essa que exclui uma perspectiva solidária e cooperativa na $A B$ do município.

Fica explícito que o compromisso assumido inicialmente pelo município não foi cumprido, sendo que o recurso advindo da adesão ao PMAQ-AB foi utilizado para outras finalidades. Isso gerou uma sensação de engodo, em todos os profissionais entrevistados de forma concordante:

A gente fez a adesão [ao PMAQ-AB], né? No primeiro [ciclo]... mas assim... [...] Mas aí, a Secretaria [Municipal de Saúde] falou assim: então... olha... vocês receberam x nota e tinha assim x grana e essa grana você poderia ver o que mais estaria precisando aqui... e a gente achou que isso foi muito mal feito pela Secretaria [Municipal de Saúde] entendeu? 'A gente achou que deu umas enroladinhas na gente, tanto é que os trabalhadores resolveram não ir para a segunda [adesão] e a gente não está participando'. (E8).

[...] eu acho que essas coisas assim... medonhentas... você me desculpa, eu sinto muito, 'mas isso não me pega, não me pega mais', [...] a gente tem que ser minimamente reflexiva para entrar nessa, mas eu acho que eu já entrei em outras...eu acho que a gente que está chegando vai pegar isso e isso pode acontecer, ' mas não dessa forma... eu sinto muito'. (E2).

Assim, verifica-se um discurso que atribui o engodo como motivo do posicionamento de recusa ante a renovação do PMAQ-AB.

Esse sentido de engodo presente na formação discursiva das enfermeiras é considerado 
como central no tensionamento entre estas e a gestão, trazendo inclusive a perspectiva de não recontratualizar o PMAQ-AB como forma de resistência ao "arbítrio gerencial"19(423) da gestão.

Dessa forma, o engodo da gestão interfere no "aspecto cíclico e sistemático de melhoria contínua de qualidade"8(576), conferido ao PMAQ$\mathrm{AB}$, fragilizando o processo avaliativo na $\mathrm{AB}$. $\mathrm{A}$ recontratualização deveria ser um momento de definir novos padrões, pelas equipes e gestores municipais, a partir de prioridades locais, porém parece não ter avançado de forma geral ${ }^{8}$.

Fica claro que a relação entre enfermeiros da $\mathrm{AB}$ e gestão não é de confiança, nem de corresponsabilidade. Não há a perspectiva de participação nos processos de decisão, de conformação da avaliação implementada com o PMAQ-AB. Não surgem mecanismos ou espaços de negociação coletiva com os trabalhadores, reforçando a ideia de Paim² de que as políticas de gestão do trabalho não atendem aos interesses dos trabalhadores.

É significativo notar que, mesmo em um discurso que critica e responsabiliza a gestão, está ausente a perspectiva de organização e de luta política dos trabalhadores, que se limitam a formas de resistência pontuais, em um contexto de ausência de negociação coletiva. Parece ficar reforçada a ideia de Almeida ${ }^{7}$, de que há entre as enfermeiras uma aceitação das limitações de poder, de forma relativamente passiva.

Nos discursos dos enfermeiros, não houve a percepção de outros estímulos que justificassem a permanência no $\mathrm{PMAQ}-\mathrm{AB}$ após o município definir que não repassaria os recursos prometidos. Isso parece corroborar diretamente o observado por Moraes ${ }^{\mathbf{1 9 ( 4 2 4 )} \text { : }}$

Se a remuneração por desempenho é apenas uma 'oportunidade' a ser viabilizada pelos municípios, há que se refletir sobre que mecanismos de motivação são verificáveis para que os trabalhadores de municípios que não adotam a remuneração por desempenho vinculada aos recursos oriundos do $P M A Q-A B$ possam se engajar no programa.

Outra questão abordada na literatura sobre o PMAQ-AB é a limitação apresentada pelo programa com relação à negociação entre trabalhadores e gestão, negligenciando a questão da negociação coletiva e privilegiando a avaliação do desempenho dos trabalhadores. Essa opção feita pelo PMAQ-AB, de fato, parece promover a visão sobre o profissional na

visão de recurso e não de agente transformador quando não pontua esse aspecto como um dos integrantes da qualidade na $A B$ e não estimula a cultura de negociação do trabalho22(195).

Constataram-se distintos discursos relativos à fase de desenvolvimento do PMAQ-AB nas unidades. Um desses discursos coloca o processo como sendo burocrático e fragmentado:

Olha... o que eu sei de PMAQ-AB: um dia veio aqui [um técnico da secretaria], que já se aposentou e eu acho que... Ah... não, [uma outra pessoa] da escola, eu não sei... Vieram duas pessoas com uma apostila dessa grossura, assim, o dobro dessa. [...]'o gerente assumiu isso... mas sozinho... pôs os nossos nomes nas equipes e... Eu não sei nem o que é isso...' para te falar a verdade, isso não existe... 'esses dados estão sendo alimentados através de estatísticas' tiradas do [sistema de informação municipal] e dos nossos livros de registro de serviço [...] 'não deve ser difícil de alimentar, mas nada mudou no nosso fazer'. [...] para mim... se foi aprovado ou não... eu acho que é só para vir um dinheiro que se viesse também era prometido para algumas melhorias aqui. Não sei se compra de ar condicionado... também não veio [...]. (E2).

'[...] eu fiquei à parte desse movimento e eu não participei enem conheço as questões'. Eu sei que foi feito e tudo a [outra enfermeira] ... a [gerente da unidade] conversou com a [outra enfermeira] que fez a parte da enfermagem e a Dentista fez a parte da Odonto e os médicos... 'não houve um encontro de equipes para discutir as questões... e eu imagino que seja assim que você tenha feito [...] Eu acho ruim não ter participado porque eu trabalho em grupo, não é? Então na minha opinião, entre nós, deveria ter sido feito com toda a equipe... mas não aconteceu'. (E6). 
A partir do enunciado de E2, observa-se processo marcado pelo 'arbítrio gerencial' inclusive no momento da adesão, quando a enfermeira coloca que o gerente colocou os nomes dos trabalhadores, porém deixa claro que o preenchimento da avaliação foi feito sem o envolvimento dos trabalhadores, de forma a dissociar a concepção do trabalho e sua execução, em um sentido de alienação: não houve mudança no fazer dos trabalhadores.

O discurso da enfermeira E6 traz uma fragmentação do desenvolvimento da avaliação, remetendo à ausência de reflexão sobre o processo de trabalho no momento da aplicação do PMAQ-AB na unidade.

Fica evidente que a assinatura da equipe na adesão e contratualização de indicadores e monitoramento não evita processos de 'arbítrio gerencial', ao contrário do que afirma o então Diretor do Departamento de Atenção Básica² ${ }^{23}$. Além da fragmentação vista no discurso da enfermeira E6, em que cada profissional realizaria a parte do questionário relativaaseu trabalho de forma burocrática, pode-se ver, no discurso das enfermeiras E8 e E3 abaixo, referências ao envolvimento heterogêneo dos profissionais, em um contexto de "dificuldade de envolver o profissional médico na construção do processo"24(202), reforçando a noção deum processo de baixa participaçãono PMAQ-AB.

[...] eu acho que os médicos um pouco desestimulados com [o PMAQ-AB]. [...] o meu dentista não gosta e não tem perfil [para PSF], e ele foi mandado para cá, porque ele era de oito horas e a gente tinha que fechar uma equipe, mas ele não participa das reuniões de equipe entendeu? 'É... só consta o nome, mas não se envolve, né?' [...]. (E8).

[Os médicos] não são teoricamente de saúde da família, né? Então a carga horária muito curta e fica aqui pouco tempo e 'os médicos não se envolveram muito...' mas os dentistas, o pessoal auxiliar tanto de farmácia e de enfermagem, os enfermeiros... o pessoal se envolveu. (E3).

Isso pode esvaziar de sentido o processo de avaliação do PMAQ-AB, que se propõe a ser: um dispositivo que convoca ao envolvimento e protagonismo dos diversos atores e amplia a possibilidades de construção de ambientes participativos dialógicos, nos quais gestores, trabalhadores e usuários se mobilizam para se comprometerem com objetivos comuns ${ }^{23(5)}$.

No entanto, isso não se efetiva na realidade retratada pelas enfermeiras entrevistadas.

A maneira como a gestão impõe a adesão prejudica a possibilidade do PMAQ-AB como um mecanismo indutor de reflexão e mudança por meio da autoavaliação e do planejamento. A possibilidade de processos dialogados que alterem, de fato, os processos de trabalho pressupõe reconhecimento dos conflitos por parte das equipes e dos gestores ${ }^{25}$, o que não ocorreu.

Apesar desse esvaziamento do processo de avaliação, há enfermeiras que valorizam a adesão da unidade ao PMAQ-AB como uma oportunidade de reflexão do processo de trabalho, mesmo tendo a mesma percepção de engodo das enfermeiras, já discutida acima.

[...] nós não estamos trabalhando pelo dinheiro. $O$ ideal seria que a verba que vem fosse para melhorar a qualidade do atendimento que nós prestamos, porém como esse incentivo, vamos dizer assim, né? Não foi cumprido... nós falamos assim: ó... nós estamos, nós continuamos trabalhando, temos muito no que a gente pode melhorar, sim... então... vamos continuar, né? [...] 'É lógico que... assim... uma avaliação é sempre muito bem-vinda, porque você para e pensa: peraí, será que o que eu estou fazendo está sendo efetivo ou não?'. (E1).

[...] lendo o questionário: olha, nós não fazemos assim e é legal fazer, vamos fazer? De propor melhorias no que está sendo feito: e a gente faz e está bom e isso aí a gente não pode melhorar, o que a gente pode melhorar então? Reflete... como é que fala... 'faz a gente refletir sobre a prática e o que pode ser feito para melhorar [...]'. (E6).

Assim, aparece como possibilidade o envolvimento dos trabalhadores em um processo que 
traga a avaliação não como um processo negativo, mas, sim, como uma oportunidade de correção e adequação de ações na $A^{26}$. Percebe-se, no trecho abaixo, um discurso que compreende o PMAQ-AB como uma oportunidade de autoavaliação, e atribui aos problemas da gestão municipal a desmotivação da equipe.

Olha... eu vejo de uma forma positiva e negativa, porque 'o processo de se autoavaliar... isso foi incorporado por essa equipe', então permitir que a gente olhe para o trabalho, reveja e busque alternativas isso a unidade toda conseguiu fazer, mas acaba tendo vindo da Secretaria [Municipal de Saúde] uma demanda financeira, né? [...] Aí a gente foi entendendo no percurso que... assim... 'esse dinheiro então chega, fica no fundo municipal e a gente não pode estar usando para atividades na unidade, para melhorias na unidade'. A Prefeitura avalia qual outra unidade precisa, às vezes, é outra unidade que nem participou do PMAQ-AB. Então... 'acabou desmotivando a equipe [...] parte da equipe comenta que não quer mais participar do PMAQ-AB, não porque a avaliação foi ruim, ou que deu trabalho, ou deu problema, ou pelo próprio processo de trabalho $[. . .]^{\prime}$. E, esse dinheiro sendo desviado ou redirecionado, em contra partida 'a gente vive um momento político muito ruim na cidade, de má gestão, de problemas com a prefeitura, com a prefeita, e greve e um monte de outros problemas que foram desmotivando a equipe para continuar participando do $P M A Q-A B^{\prime}$. (E3).

Ao perceber que o recurso do PMAQ-AB é incorporado ao fundo municipal, o discurso coloca como prerrogativa da gestão municipal decidir o uso desse recurso. O componente da $\mathrm{PAB}$ Variável decorrente da adesão ao PMAQ-AB é transferido fundo a fundo, do Fundo Nacional para o Fundo Municipal de Saúde, sem que seja previsto pelo programa, a princípio, um sistema de recompensas que atinja diretamente as equipes de $\mathrm{AB}$ que realizaram a adesão ${ }^{19}$.

Assim, no caso dos trabalhadores da $\mathrm{AB}$ de Ribeirão Preto, segundo o discurso da enfermeira E3, fica atribuída à condução da gestão municipal a desmotivação relativa à implementação da ferramenta do PMAQ-AB, a partir de significados negativos referidos à gestão, não somente quanto ao PMAQ-AB, mas ao contexto político existente no município no momento do estudo conforme destacado.

\section{Considerações finais}

Não se tem a pretensão de esgotar a dimensão política do trabalho do enfermeiro na $\mathrm{AB}$, tendo em vista a amplitude dessa temática, nem mesmo de esgotar o conflito estudado. Objetivou-se discutir alguns dos aspectos mais presentes no discurso encontrado nas entrevistas, apresentando situações de interesse nesse debate em relação à contratualização e à recontratualização do PMAQ-AB, sendo que se optou por pesquisar unidades nas quais esse conflito estava presente. Considera-se que isso constitui uma limitação do presente estudo, já que outras perspectivas podem estar presentes entre outros trabalhadores da rede municipal.

Não obstante as dificuldades vividas pelos grandes municípios na implementação da $\mathrm{AB}$, o que se vê no caso estudado é a realidade de uma transição incompleta de modelo de $\mathrm{AB}$, mais como mistura do que transição, com uma implantação incipiente e incompleta da ESF, apesar dos documentos de planejamento municipais reiteradamente colocarem essa estratégia como a opção municipal para a AB.

Quando se adicionam os relatos dos enfermeiros aos documentos, percebe-se, também, que esses processos incompletos se dão em contexto de conflitos e descontinuidades, que geram descrédito nos modelos e nas políticas a serem implementadas. De fato, o constante jogo de mudanças de políticas conforme ocorre as trocas de governo ou de gestor, com frequentes ingerências políticas na distribuição dos quadros técnicos, abalam a sustentabilidade institucional do SUS.

A implementação do PMAQ-AB no município estudado não constituiu um espaço de reflexão, negociação e cogestão. A forma como o processo foi conduzido, segundo os discursos, privilegiou os aspectos burocráticos, esvaziando a política de avaliação de sentido para os trabalhadores. 
Neste momento histórico em que os princípios fundamentais da $\mathrm{AB}$ e do SUS têm sido postos em xeque, com a proposição de um modelo de financiamento que privilegia a focalização, feito por um grupo político que visa à descontinuidade da avaliação não por questões técnicas, mas por ser avesso ao SUS e às políticas sociais, entende-se que é de particular importância olhar para a dimensão política no sentido de buscar agentes sociais que sigam defendendo o SUS enquanto projeto civilizatório.

\section{Colaboradores}

Carneiro TSG (0000-0001-9480-2052)* contribuiu substancialmente para a concepção, planejamento, análise e a interpretação dos dados; contribuiu significativamente para a elaboração do rascunho e revisão crítica do conteúdo e participou da aprovação da versão final do manuscrito. Carneiro PS (0000-00033873-8951)* contribuiu substancialmente para a análise e a interpretação dos dados; contribuiu significativamente para a elaboração do rascunho e participou da aprovação da versão final do manuscrito. Pinto IC (00000001-7541-5591)* contribuiu substancialmente para a concepção e o planejamento; contribuiu significativamente para a revisão crítica do conteúdo e participou da aprovação da versão final do manuscrito.

\section{Referências}

1. Souza LEPF. O SUS necessário e o SUS possível: gestão. Uma reflexão a partir de uma experiência concreta. Ciênc. Saúde Colet. [internet]. 2009 [acesso em 2019 ago 7]; 14(3):911-918. Disponível em: http:// dx.doi.org/10.1590/S1413-81232009000300027.

2. Paim JS. Sistema Único de Saúde (SUS) aos 30 anos. Ciênc. Saúde Colet. [internet]. 2018 [acesso em 2019 ago 7]; 23(6):1723-1728. Disponível em: http://dx.doi. org/10.1590/1413-81232018236.09172018.

3. Santos NR. SUS 30 anos: o início, a caminhada e o rumo. Ciênc. Saúde Colet. [internet]. 2018 [acesso em 2019 ago 7]; 23(6):1729-1736. Disponível em: http:// dx.doi.org/10.1590/1413-81232018236.06092018.

4. Campos GWS. SUS: o que e como fazer? Ciênc. Saúde Colet. [internet]. 2018 [acesso em 2019 ago 7]; 23(6):1707-1714. Disponível em: http://dx.doi. org/10.1590/1413-81232018236.05582018.

5. Pinto LF, Giovanella L. Do Programa à Estratégia Saúde da Família: expansão do acesso e redução das internações por condições sensíveis à atenção básica (ICSAB). Ciênc. Saúde Colet. [internet]. 2018 [acesso em 2019 ago 7]; 23(6):1903-1914. Disponível em: http:// dx.doi.org/10.1590/1413-81232018236.05592018.
*Orcid (Open Researcher and Contributor ID). 
6. Cunha GT. Atenção Básica e o desafio do SUS. In: Brasil. Ministério da Saúde, Secretaria de Atenção à Saúde. Política Nacional de Humanização. Política Nacional de Humanização. Brasília, DF: MS; 2014. (Cadernos Humaniza SUS; v. 2).

7. Almeida MCP, Rocha SMM. O trabalho de Enfermagem. São Paulo: Cortez; 1997.

8. Giovanella L, Mendonça MHM, Medina MG, et al. Contribuições dos Estudos PMAQ-AB para a avaliação da APS no Brasil. In: Mendonça MHM, Matta GC, Gon$\operatorname{dim} \mathrm{R}$, et al., organizadores. Atenção Primária à Saúde no Brasil. Rio de Janeiro: Fiocruz, 2018. p. 569-610.

9. Brasil. Ministério da Saúde. Portaria $n^{0} 1.654$, de 19 de julho de 2011. Institui, no âmbito do Sistema Único de Saúde, o Programa Nacional de Melhoria do Acesso e da Qualidade da Atenção Básica (PMAQ-AB) e o Incentivo Financeiro do PMAQ-AB, denominado Componente de Qualidade do Piso de Atenção Básica Variável - PAB Variável [internet]. Diário Oficial da União. Brasília, DF. 20 Jul 2011. [acesso em 2019 nov 26]. Disponível em: http://bvsms.saude.gov.b r/ bvs/saudelegis/gm/2011/prt1654_19_07_2011.html.

10. Brasil. Ministério da Saúde. Portaria $n^{0} 1.645$, de 2 de outubro de 2015. Dispõe sobre o Programa Nacional de Melhoria do Acesso e da Qualidade da Atenção Básica (PMAQ-AB) [internet]. Brasília, DF; 2015 [acesso em 2019 ago 16]. Disponível em: http://bvsms.saude.gov. br/bvs/saudelegis/gm/2015/prt1645_01_10_2015.html.

11. Brasil. Ministério da Saúde, Secretaria de Atenção à Saúde. Departamento de Atenção Básica. Programa Nacional de Melhoria do Acesso e da Qualidade da Atenção Básica (PMAQ-AB): manual instrutivo [internet]. Brasília, DF; 2012 [acesso em 2018 jul 10]. Disponível em: http://bvsms.saude.gov.br/bvs/ publicacoes/manual_instrutivo_programa_acesso_ atencao_basica_site.pdf.

12. Stake RE. Case Studies. In: Denzin N, Lincoln SY. Strategies of Qualitative Inquiry. Thousand Oaks: Sage Publications Inc.; 2003. p. 134-164.

13. Orlandi, EP. Análise de discurso: princípios e proce- dimentos. 11. ed. Campinas: Pontes; 2013.

14. Instituto Brasileiro de Geografia e Estatística (IBGE) [internet]. Cidades. Brasília, DF: IBGE; 2019. [acesso em 2019 jul 30]. Disponível em: http://cidades.ibge. gov.br/xtras/perfil.php?lang=\&codmun=354340\&se arch=saopauo|ribeirao-preto.

15. Ribeirão Preto. Prefeitura Municipal, Secretaria Municipal de Saúde. Plano Municipal de Saúde (2018-2021): 2017 [internet]. Ribeirão Preto; 2017 [acesso em 2019 nov 26]. Disponível em: https://www.ribeiraopreto. sp.gov.br/ssaude/pdf/pms-rp-2018-2021.pdf.

16. Brasil. Ministério da Saúde. Gabinete do Ministro. Portaria $\mathrm{n}^{\circ} 2.488$, de 21 de outubro de 2011. Aprova a Política Nacional de Atenção Básica, estabelecendo a revisão de diretrizes e normas para a organização da Atenção Básica, para a Estratégia Saúde da Família (ESF) e o Programa de Agentes Comunitários de Saúde (PACS) [internet]. Diário Oficial da União. 22 Out 2011. [acesso em 2019 nov 26]. Disponível em: http://bvsms.saude.gov.br/bvs/saudelegis/gm/2011/ prt2488_21_10_2011.html.

17. Brasil. Ministério da Saúde, Secretaria Executiva, Subsecretaria de Planejamento e Orçamento. Sistema de planejamento do SUS: uma construção coletiva - perfil da atividade do planejamento no Sistema Único de Saúde: resultados da pesquisa - esfera municipal. Brasília, DF: MS; 2008.

18. Sznelwar LI, Abraão JI. Introdução: abordagens e desafios no trabalho no PSF. In: Viana ALA, Novaes HMD, Silva JÁ, coordenadores. Inquérito com usuários e profissionais, percepção dos gestores e estudos sobre o trabalho no PSF. São Paulo: Centro de Estudos de Cultura Contemporânea: Consórcio Medicina USP; 2007. (Cadernos de Atenção Básica: estudos avaliativos, 3). p. 107-128.

19. Moraes PN, Iguti AM. Avaliação do desempenho do trabalhador como forma peculiar de prescrição do trabalho: uma análise do PMAQ-AB. Saúde debate [internet]. 2013 [acesso em 2019 nov 28]; 37(98):416-426. Disponível em: http://www.scielo.br/scielo.php?script=sci_arttext\&pid=S0103- 
$-11042013000300005 \& \operatorname{lng}=$ en. http://dx.doi. org/10.1590/S0103-11042013000300005.

20. Ribeirão Preto. Prefeitura Municipal, Secretaria Municipal de Saúde. Relatório de Gestão: 2012 [internet]. Ribeirão Preto; 2012. [acesso em 2019 nov 26]. Disponível em: https://www.ribeiraopreto.sp.gov.br/ssaude/pdf/2012_relatorio_gestao.pdf.

21. Ribeirão Preto. Prefeitura Municipal, Secretaria Municipal de Saúde. Plano Municipal de Saúde: 2014 [internet]. Ribeirão Preto; 2014. [acesso em 2019 nov 26]. Disponível em: https://www.ribeiraopreto.sp.gov.br/ ssaude/pdf/pms-rp-2014-2017.pdf.

22. Bezerra MM, Medeiros KR. Limites do Programa de Melhoria do Acesso e da Qualidade da Atenção Básica (PMAQ-AB): em foco, a gestão do trabalho e a educação na saúde. Saúde debate [internet]. 2018 [acesso em 2019 jul 22]; 42(esp2):188-202. Disponível em: http://dx.doi.org/10.1590/0103-11042018s213.

23. Pinto HÁ, Sousa A, Florêncio AR. O Programa Nacional de Melhoria do Acesso e da Qualidade da Atenção Básica: Reflexões sobre o seu desenho e processo de implantação. RECIIS [internet]. 2012 [acesso em 2020 abr 1]; 6(2). Disponível em: https://www.reciis. icict.fiocruz.br/index.php/reciis/article/view/492.
24. Linhares PHA, Lira GV, Albuquerque IMN. Avaliação do Programa Nacional de Melhoria do Acesso e da Qualidade da Atenção Básica no estado do Ceará. Saúde debate [internet]. 2014 [acesso em 2019 nov 27]; 38(esp):195-208. Disponível em: http://www. scielo.br/scielo.php?script=sci_arttext\&pid=S0103$-11042014000600195 \& \operatorname{lng}=$ en.

25. Cruz MM, Souza RBC, Torres RMC, et al. Usos do planejamento e autoavaliação nos processos de trabalho das equipes de Saúde da Família na Atenção Básica. Saúde debate [internet]. 2014 [acesso em 2019 nov 26]; 38(esp):124-139. Disponível em: http://www. scielo.br/scielo.php?script=sci_arttext\&pid=S0103$-11042014000600124 \& \operatorname{lng}=$ en.

26. Rodrigues V, Santos CRI, Pereira MU. A experiência de planejar e operacionalizar o PMAQ-AB no estado do Acre. Saúde debate [internet]. 2014 [acesso em 2019 nov 28]; 38(esp):173-181. Disponível em: http://www. scielo.br/scielo.php?script=sci_arttext\&pid=S0103$-11042014000600173 \& \operatorname{lng}=e n$.

Recebido em 29/08/2019

Aprovado em 21/01/2020

Conflito de interesses: inexistente

Suporte financeiro: Coordenação de Aperfeiçoamento de Pessoal

de Nível Superior - Brasil (Capes) 